\title{
Daily consumption of a high-phenol extra-virgin olive oil reduces oxidative DNA damage in postmenopausal women
}

\author{
Simonetta Salvini ${ }^{1}$, Francesco Sera ${ }^{1}$, Donatella Caruso $^{2}$, Lisa Giovannelli ${ }^{3}$, Francesco Visioli ${ }^{2}$, \\ Calogero Saieva ${ }^{1}$, Giovanna Masala ${ }^{1}$, Marco Ceroti ${ }^{1}$, Valentina Giovacchini ${ }^{1}$, Vanessa Pitozzi ${ }^{3}$, \\ Claudio Galli ${ }^{2}$, Annalisa Romani ${ }^{4}$, Nadia Mulinacci ${ }^{4}$, Renzo Bortolomeazzi ${ }^{5}$, Piero Dolara ${ }^{2}$ and \\ Domenico Palli ${ }^{1}$ \\ ${ }^{1}$ Molecular and Nutritional Epidemiology Unit, Centro per lo Studio e la Prevenzione Oncologica (CSPO), Scientific Institute of \\ Tuscany, Florence, Italy \\ ${ }^{2}$ Department of Pharmacological Sciences, University of Milan, Milan, Italy \\ ${ }^{3}$ Department of Preclinical and Clinical Pharmacology, University of Florence, Florence, Italy \\ ${ }^{4}$ Department of Pharmaceutical Sciences, University of Florence, Florence, Italy \\ ${ }^{5}$ Department of Food Science, University of Udine, Udine, Italy
}

(Received 6 June 2005 - Revised 3 November 2005 - Accepted 22 November 2005)

\begin{abstract}
Extra-virgin olive oils (EVOO), high in phenolic compounds with antioxidant properties, could be partly responsible for the lower mortality and incidence of cancer and CVD in the Mediterranean region. The present study aims to measure oxidative DNA damage in healthy human subjects consuming olive oils with different concentrations of natural phenols. A randomised cross-over trial of high-phenol EVOO (high-EVOO; $592 \mathrm{mg}$ total phenols $/ \mathrm{kg}$ ) v. low-phenol EVOO (low-EVOO; $147 \mathrm{mg} / \mathrm{kg}$ ) was conducted in ten postmenopausal women in Florence. Subjects were asked to substitute all types of fat and oils habitually consumed with the study oil $(50 \mathrm{~g} / \mathrm{d})$ for 8 weeks in each period. Oxidative DNA damage was measured by the comet assay in peripheral blood lymphocytes, collected at each visit during the study period. Urine samples over $24 \mathrm{~h}$ were collected to measure the excretion of the olive oil phenols. The average of the four measurements of oxidative DNA damage during treatment with high-EVOO was $30 \%$ lower than the average during the low-EVOO treatment $(P=0.02)$. Urinary excretion of hydroxytyrosol and its metabolite homovanillyl alcohol were significantly increased in subjects consuming high-EVOO. Despite the small sample size, the present study showed a reduction of DNA damage by consumption of an EVOO rich in phenols, particularly hydroxytyrosol.
\end{abstract}

Extra-virgin olive oil: Phenols: Hydroxytyrosol: Oxidative DNA damage: Cancer

In recent years, evidence has accumulated of a lower mortality and incidence of cancer and CVD in the Mediterranean area, with regard to the rest of Europe and other parts of the industrialised world (Owen et al. 2004). Various aspects of diet have been hypothesised as possible determinants of this effect, but the most characterising dietary habit in this area is the daily consumption of olive oil as the main fat used for seasoning and for food preparation. Other hypothesised health-enhancing ingredients, such as vegetables, fruit, whole grains, nuts, fish, and possibly red wine, are commonly consumed also in other parts of the Western world, and their benefit for reducing chronic diseases can be observed even within non-Mediterranean countries.

We know much less about the effects of different qualities of olive oils. This quality is defined by European regulations (European Commission, 2003), which state the requirements for each commercial type of olive oil: extra-virgin, virgin, olive oil, and finally olive-pomace oil. Even extra-virgin olive oils (EVOO) can differ in terms of their MUFA content, tocopherols, and a large variety of minor polar components, mainly phenols. The phenolic fraction includes hydroxytyrosol and its precursors that have potent antioxidant capacity due to their catecholic moiety (Montedoro et al. 1992a,b). It is noteworthy that olive oil phenols are absorbed and excreted by animals (Visioli et al. 2001) and man (Visioli et al. 2000b; Vissers et al. 2001). Researchers have focused their attention on the hypothesised reduction of oxidation of LDL by olive oil phenols, which could potentially reduce atherosclerosis; some results have been encouraging but others have not (Vissers et al. 2001; Gimeno et al. 2002; Moschandreas et al. 2002).

A possible role of hydroxytyrosol in protecting DNA from oxidative damage has been shown in vitro (Deiana et al. 1999) and only recently also in vivo (Weinbrenner et al. 2004). We therefore planned a pilot study to assess in vivo,

Abbreviations: EPIC, European Prospective Investigation into Cancer and Nutrition; EVOO, extra-virgin olive oil; high-EVOO, high-phenol extra-virgin olive oil; HVAlc, homovanillyl alcohol; low-EVOO, low-phenol extra-virgin olive oil.

* Corresponding author: Dr Simonetta Salvini, fax +39055 32697829, email s.salvini@cspo.it 
in subjects consuming their habitual diets, the antioxidant effects of an EVOO rich in naturally occurring phenols and compare it with a similar quality EVOO with a concentration of phenols in the lower range of what is commonly available on the Italian market.

\section{Materials and methods}

Study design

A randomised cross-over intervention trial of high-phenol EVOO (high-EVOO) v. low-phenol EVOO (low-EVOO) was planned, to evaluate their effects on oxidative DNA damage in healthy volunteers.

The present pilot study consisted of two intervention periods of 8 weeks each, the first in September-November 2002, and the second after an 8-week wash-out period, in January-March 2003. Participants were randomised to the sequence of consumption of the two study oils (high-EVOO in the first period and low-EVOO in the second period, or vice versa), and were asked to substitute all fats and oils usually consumed for seasoning and food preparation with the specifically selected study oils, and to consume at least $50 \mathrm{~g}$ daily of the assigned study oils in raw form in addition to the study oils necessary for cooking. Subjects were also asked to use the study oils when preparing the meals for other members of the family and when eating away from home. Therefore, study oils were provided at each visit in a quantity estimated to be sufficient for the whole family for a period of 2 weeks. Study participants and personnel were unaware of the treatment assignment. However, because of the very marked difference between the taste of a phenol-rich and a phenol-poor oil, at follow-up visits the study personnel had quite clear clues from volunteers concerning their study oil consumption. These perceptions were not disclosed to study subjects.

Apart from the fat substitution, subjects were instructed to stay on their habitual diet. Volunteers were seen at our clinic on ten occasions (at the baseline and thereafter every 2 weeks) for body measurements (height at the first visit, and weight, waist and hip circumferences), blood pressure and heart rate, blood drawing, $24 \mathrm{~h}$ urine collection and $24 \mathrm{~h}$ diet recall interview at the baseline and at each subsequent visit. In addition to these procedures, at the baseline visit subjects were asked to report their dietary and lifestyle habits by filling in the European Prospective Investigation into Cancer and Nutrition (EPIC) study self-administered food-frequency questionnaire and lifestyle questionnaire (Pala et al. 2003). At the last visit in each of the two periods (fifth and tenth visit), subjects were asked questions about the acceptance of the assigned treatment and about their participation in the trial.

During the whole study period, subjects were seen at the study clinic ten times; five times in the first study period and five times in the second. During the 8-week washout, they were asked to consume their habitual fats and oils.

\section{Subjects}

Flyers about the study were distributed and posted in our clinics and among women's health initiative groups. Selection criteria included being a healthy postmenopausal woman (no menstrual periods in the previous 12 months), non-smoker, with no history of treated hypercholesterolaemia and/or hypertension, no chronic use of aspirin or antioxidant vitamins, and without history of cancer, CVD, diabetes or other important chronic conditions. Criteria for eligibility also included residing in the Florence area, consuming most of the meals at home (no more than two meals per week outside home) and consuming less than two glasses red wine per $\mathrm{d}$ to avoid interference between the effects of red wine phenols and the olive oil phenols. Interested subjects were asked to contact us by telephone, and were asked specific questions checking for eligibility criteria. Out of thirty-five women who contacted us, thirteen were found eligible and twelve agreed to enter the trial. Selected women were invited to a meeting in which the study was described in detail, and printed material and informed consent forms were provided to the subjects. Individual appointments for the baseline visit were set up and volunteers were instructed to collect their urine during the $24 \mathrm{~h}$ before the visit. Three 1 litre, disposable containers were given for urine collection, together with a $1 \mathrm{ml}$ vial of $40 \mu \mathrm{M}$-butylated hydroxytoluene to be poured into each container just before starting the urine collection. Subjects were requested to dispose of the first urine in the morning of the collection day and to collect subsequently each voided urine in the following $24 \mathrm{~h}$, including the first urine on the following day. At each visit, subjects were given containers for the following urine collection.

Before starting the second phase of the trial (after 8 weeks washout), two women, both initially assigned to the lowphenol olive oil, discontinued their participation. Ten volunteers were therefore left for the analyses. The flow of study subjects is presented in Fig 1.

\section{Dietary intake measurements}

At baseline, dietary habits were measured by the EPIC foodfrequency questionnaire. Frequencies of consumption of standard or specifically reported portions were transformed into weight $(\mathrm{g})$ of daily consumed food and daily nutrient intakes (Pisani et al. 1997; Pala et al. 2003). In addition, at each of the ten visits, subjects were interviewed by the study dietitian about food and beverages consumed in the previous $24 \mathrm{~h}$. Food consumption data were transformed into average daily consumption of food, beverages and nutrients, by means of the nutritional software Microdiet (University of Salford, UK). The software includes, in addition to UK food composition data, also the same Italian food tables applied to the EPIC food-frequency questionnaire (Salvini et al. 1998). The composition of the study oils was also entered into the software to allow estimation of daily intake of olive oil phenols during the two intervention periods.

\section{Selection of study oils}

Aiming to select a very high-phenol olive oil and one in the lower bound of possible concentrations, several batches of high-quality EVOO, originating from different parts of the Mediterranean basin, were selected and analysed. All selected oils were in line with commercial requirements for EVOO, showing very low acidity (range $0 \cdot 1-0.8 \%$ ) and low total 


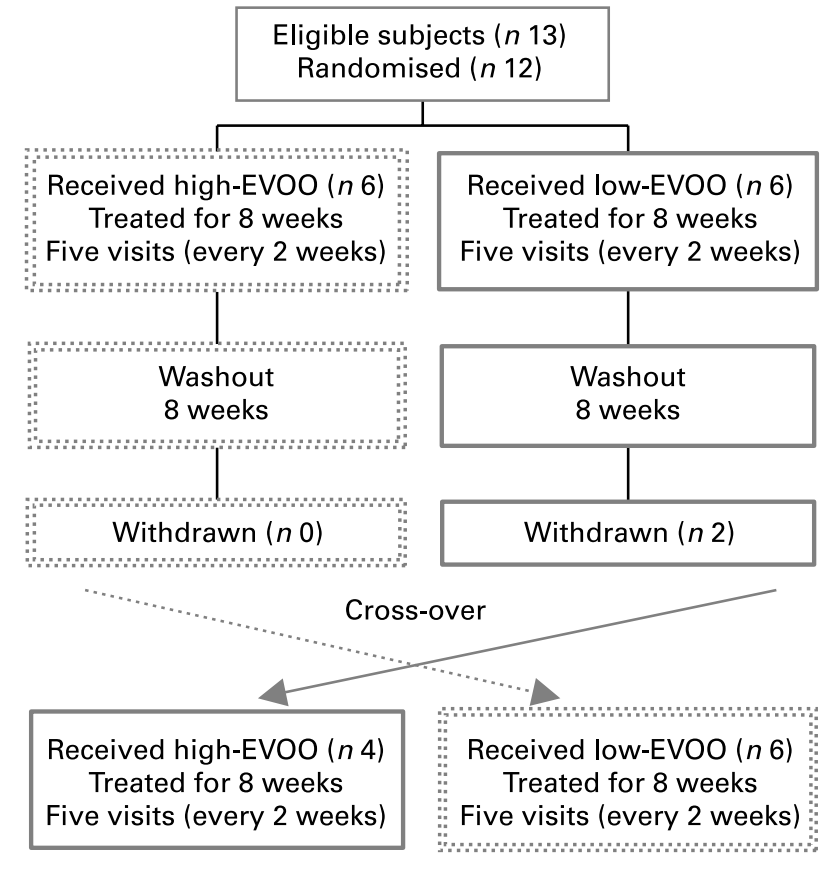

Completed trial $(n 10)$

Fig. 1. Trial profile, summarising the flow of the study subjects. High-EVOO, high-phenol extra-virgin olive oil; low-EVOO, low-phenol extra-virgin olive oil. For details of subjects and procedures, see p. 743

peroxides $\left(1 \cdot 8-12 \cdot 3\right.$ meq $\left.\mathrm{O}_{2} / \mathrm{kg}\right)$. The concentration of MUFA ranged from 73.9 to $79.4 \%$, and $\alpha$-tocopherol varied from 135 to $290 \mathrm{mg} / \mathrm{kg}$. Total phenols ranged from 87 to $806 \mathrm{mg} / \mathrm{kg}$ and also the fraction of free hydroxytyrosol showed a very large variation $(0 \cdot 4-19 \mathrm{mg} / \mathrm{kg})$. After organoleptic examination by study personnel to test the palatability of the samples, the final selection was made. A blend of Italian EVOO, predominantly from the southern Italian region of Puglia (mostly Coratina cultivar), was chosen as the high-phenol oil (total phenols $592 \mathrm{mg} / \mathrm{kg}$ ), and a sample of a blend of EVOO mainly from the Liguria region was chosen as the lowphenol olive oil (total phenols $147 \mathrm{mg} / \mathrm{kg}$ ). The main chemical characteristics of the selected olive oils are shown in Table 1.

To measure the total phenols in the study oils, extraction and HPLC-diode array detection-MS analysis were applied according to previous studies (Romani et al. 2001; Pinelli et al. 2003; Mulinacci et al. 2006b). The free and linked form of hydroxytyrosol were evaluated after the acidic hydrolysis of the phenolic olive oil fraction (Mulinacci et al. 2006a).

For the analysis of the fatty acids, a Fisons 8060 gas chromatograph equipped with a split-splitless injector and a flame ionisation detector was used. The fused silica column was an SP $2380,30 \mathrm{~m} \times 0.32 \mathrm{~mm}$ internal diameter, $0.20 \mu \mathrm{m}$ film thickness (Supelco, Bellefonte, PA, USA). The column temperature was set at $165^{\circ} \mathrm{C}$ for $5 \mathrm{~min}$, then programmed to $220^{\circ} \mathrm{C}$ at $5^{\circ} \mathrm{C} / \mathrm{min}$ followed by $10 \mathrm{~min}$ isotherm. The injector and detector temperature was $220^{\circ} \mathrm{C}$. The carrier gas $(\mathrm{He})$ flow-rate was $0.6 \mathrm{ml} / \mathrm{min}$. The fatty acids were analysed as methyl ester derivatives prepared by trans-esterification with a cold methanolic solution of potassium hydroxide (IUPAC standard method 2.301; IUPAC, 1987).

The tocopherols composition was determined by normalphase HPLC with spectrofluorometric detection (Dieffenbacher \& Pocklington, 1992). A Knauer K-501 pump equipped with a Jasco FP-1520 fluorescence detector $\left(\lambda_{\mathrm{ex}} 290 \mathrm{~nm}, \lambda_{\mathrm{em}}\right.$ $330 \mathrm{~nm}$ ) and a silica column Spherisorb S5W, $250 \mathrm{~mm} \times 4.6 \mathrm{~mm}$ internal diameter, $5 \mu \mathrm{m}$ particle size was used. The elution was carried out in isocratic condition with $n$-hexane containing $1 \%(\mathrm{v} / \mathrm{v})$ isopropyl alcohol as the mobile phase. A sample of $250 \mathrm{mg}$ oil was dissolved in $25 \mathrm{ml}$ mobile phase in a volumetric flask before analysis.

\section{Biological markers}

Peripheral blood $(30 \mathrm{ml})$ was collected from an antecubital vein at each visit. Blood was drawn in different vacutainers depending on the analyses to be performed. Samples for comet assay were sent within $3 \mathrm{~h}$ from collection to the appropriate laboratory. Additional samples drawn in EDTA and in lithium heparin were centrifuged at $3200 \mathrm{~g}$ for $20 \mathrm{~min}$ : plasma, buffy coat, and erythrocytes were separated into $1 \mathrm{ml}$ vials and stored at $-80^{\circ} \mathrm{C}$ in alarmed freezers until shipment to the appropriate laboratory or stored for future analyses. All analyses were carried out blinded to study identifiers by laboratory personnel.

Comet assay. One EDTA tube was brought within $3 \mathrm{~h}$ from collection to the laboratory for analyses of DNA damage. Lymphocytes were isolated utilising Lymphoprep separation medium (Gibco, UK). Blood samples of $3 \mathrm{ml}$ were diluted 1:2 with PBS and layered on an equal volume of Lymphoprep medium in a centrifuge tube. After centrifugation at $1000 \mathrm{~g}$ for $20 \mathrm{~min}$, gradient-separated lymphocytes were recovered, diluted 1:4 with PBS and centrifuged again at $1000 \mathrm{~g}$ for $10 \mathrm{~min}$. The resulting cell pellets were re-suspended in PBS and counted in a Neubauer chamber.

Table 1. Composition of the selected study oils in terms of phenols and tocopherols $(\mathrm{mg} / \mathrm{kg}$ ) and fatty acids (\%)

\begin{tabular}{|c|c|c|}
\hline & \multicolumn{2}{|c|}{ Study oils } \\
\hline & Low-EVOO & High-EVOO \\
\hline Hydroxytyrosol (free form) & 1.6 & $12 \cdot 2$ \\
\hline Tyrosol & $2 \cdot 6$ & $14 \cdot 6$ \\
\hline Elenolic acid derivatives & $2 \cdot 4$ & $6 \cdot 7$ \\
\hline Elenolic acid & $13 \cdot 5$ & $47 \cdot 9$ \\
\hline 3,4-DHPEA-EDA* & $4 \cdot 7$ & $51 \cdot 3$ \\
\hline Total secoiridoids derivatives & $114 \cdot 8$ & 351.4 \\
\hline Oleuropein aglycone & $6 \cdot 3$ & $107 \cdot 6$ \\
\hline Luteolin & $1 \cdot 2$ & 0.2 \\
\hline Total phenols & $147 \cdot 3$ & $591 \cdot 8$ \\
\hline Total hydroxytyrosol† & $15 \cdot 4$ & $157 \cdot 3$ \\
\hline$\alpha$-Tocopherol & $220 \cdot 0$ & $275 \cdot 0$ \\
\hline$\beta$-Tocopherol & $1 \cdot 1$ & $2 \cdot 0$ \\
\hline$\gamma$-Tocopherol & 1.4 & 11.9 \\
\hline Saturated fatty acids (\%) & $15 \cdot 8$ & $12 \cdot 6$ \\
\hline MUFA (\%) & $73 \cdot 8$ & $78 \cdot 5$ \\
\hline PUFA (\%) & $10 \cdot 3$ & $8 \cdot 9$ \\
\hline
\end{tabular}

High-EVOO, high-phenol extra-virgin olive oil; low-EVOO, low-phenol extra-virgin olive oil.

* 3,4 Dialdehydic form of elenolic acid linked to hydroxytyrosol.

†Free and linked forms, evaluated after acidic hydrolysis.

For details of procedures, see p. 743 . 
Membrane integrity was assessed by the trypan blue exclusion method. The comet assay was used to measure both DNA breaks and oxidised bases. Samples of the lymphocyte suspension containing about 200000 cells were further centrifuged at $250 \mathrm{~g}$ for $10 \mathrm{~min}$, and the resulting pellets were re-suspended in low-melting point agarose, layered on microscopic slides and run through the comet assay as previously described (Giovannelli et al. 2003). Detection of oxidative DNA damage was carried out by means of the enzyme formamidopyrimidine DNA glycosylase, which introduces breaks at sites of oxidised purines such as 8-oxo-2'-deoxyguanosine.

The value of DNA damage (expressed as \% DNA in the comet tail) obtained in slides without enzyme incubation estimated the basal number of DNA strand breaks, whereas specific DNA oxidative damage on purines was assessed for each subject by subtracting the percentage DNA in the comet tail found in the buffer-incubated slides from that obtained in the slides incubated with formamidopyrimidine DNA glycosylase.

Microscopic analysis was carried out by means of a Labophot-2 microscope (Nikon, Tokyo, Japan) provided with epifluorescence and equipped with a rhodamine filter (excitation wavelength $546 \mathrm{~nm}$; barrier $580 \mathrm{~nm}$ ). The images of fifty randomly chosen nuclei per slide were captured and analysed using a custom-made imaging software coupled with a CCD camera (model C5985; Hamamatsu, SunayamaCho, Japan). Each point was run in duplicate. Data were expressed as percentage DNA migrated in the tail, a parameter that is directly correlated with the number of breaks. Calibration of the method with $\gamma$-rays, which induce a known dose-dependent frequency of breaks, showed that $10 \%$ DNA in the tail corresponds to about 1.3 breaks per $10^{9}$ Da DNA.

In vitro exposure to hydrogen peroxide. In order to evaluate the response of lymphocytes to oxidative stress, samples of the isolated cells were exposed to $\mathrm{H}_{2} \mathrm{O}_{2}$ in vitro. Immediately after isolation, 400000 cells from each subject were re-suspended in $1 \mathrm{ml}$ PBS containing $25 \mu \mathrm{M}-\mathrm{H}_{2} \mathrm{O}_{2}$. This concentration of $\mathrm{H}_{2} \mathrm{O}_{2}$ was chosen on the basis of preliminary experiments in which the effect of different doses had been evaluated. The rationale for this choice was that the $25 \mu \mathrm{M}$ concentration induced an increase in DNA damage, which was significant $(+150 \%$ above basal levels) and at the same time not overly strong, so that even weak protective effects of olive oil phenols could be detected. The incubation with $\mathrm{H}_{2} \mathrm{O}_{2}$ was conducted for $5 \mathrm{~min}$ at $4^{\circ} \mathrm{C}$ to inhibit DNA repair. After completing the incubation, the lymphocytes were centrifuged at $250 \mathrm{~g}$ for $10 \mathrm{~min}$, and the resulting pellets were resuspended in low-melting point agarose (two slides for each experimental point) to be run through the comet assay as described earlier. Only DNA strand breaks were measured in this set of experiments.

Plasma antioxidant capacity. The antioxidant capacity of plasma was evaluated according to a method based on the inhibition of the radical cation 2-2'-azino-di[3-ethylbenzthiazoline sulfonate] $\left(\mathrm{ABTS}{ }^{\circledR}\right.$ ) formation (Randox Laboratories Ltd, Crumlin, Co. Antrim, UK) (Miller et al. 1993).

Olive oil phenolics in human urine. At each visit, the $24 \mathrm{~h}$ urine samples collected by the volunteers and stabilised with butylated hydroxytoluene were weighed, then mixed together if collected in more than one container, and finally sampled in fifteen $10 \mathrm{ml}$ vials and frozen at $-20^{\circ} \mathrm{C}$. Two vials for each subject were shipped in dry ice to the appropriate laboratory. For the quantification of total simple phenols in urine, 360 units $\beta$-glucuronidase (Sigma, St Louis, MO, USA) were added to $1 \mathrm{ml}$ urine after thawing and incubated overnight at $37^{\circ} \mathrm{C}$ and $\mathrm{pH} \mathrm{5}$. At the end of incubation, each sample was added with ${ }^{2} \mathrm{H}$-labelled hydroxytyrosol $(0.5 \mu \mathrm{g} /$ $\mathrm{ml})$ and $\alpha$-naphthole $(1 \mu \mathrm{g} / \mathrm{ml})$, as internal standards for hydroxytyrosol and for its metabolite homovanillyl alcohol (HVAlc), respectively. After acidification with $0.3 \mathrm{M}-\mathrm{HCl}-$ acetonitrile $(1: 1, \mathrm{v} / \mathrm{v})$, urine was extracted twice with three volumes of ethyl acetate; the organic phase was evaporated to dryness under $\mathrm{N}_{2}$. The residue was derivatised with a mixture of bis-trimethylsilyl-trifluoro acetamide-pyridine (4:1, v/ v) before the GC-MS analysis. Calibration curves were prepared using $1 \mathrm{ml}$ samples of urine that did not contain the compounds under investigation. These samples were spiked with ${ }^{2} \mathrm{H}$-labelled hydroxytyrosol $(0.5 \mu \mathrm{g} / \mathrm{ml})$ and $\alpha$-naphthole $(1 \mu \mathrm{g} / \mathrm{ml})$ and increasing amounts $(10-2000 \mathrm{ng} / \mathrm{ml})$ of authentic hydroxytyrosol and its metabolites; each sample was then extracted and analysed, as already described. GC-MS analyses were performed on a CP-Syl8 fused silica capillary column (Varian Inc., Palo Alto, CA, USA) connected with a GCQ mass spectrometer (ThermoQuest, Petterson, CA, USA). Ions at $\mathrm{m} / \mathrm{z} 216$ for $\alpha$-naphthole, at $\mathrm{m} / \mathrm{z} 312$ for HVAlc, 370 and 372 for natural and ${ }^{2} \mathrm{H}$-labelled hydroxytyrosol respectively, were recorded. These ions are selected after mass spectra obtained from authentic standards (Caruso et al. 2001).

Routine examinations. At the first and last visits of each of the two treatment periods, a sample was also drawn for routine laboratory examination. These samples were assayed by standard procedures at the central laboratory of the Careggi Hospital (Florence, Italy).

\section{Statistical analysis}

Descriptive statistics were calculated to provide general information on the sample of volunteers.

To evaluate the effect of treatment, of period and to test the presence of carry-over, responses obtained during the first period (September-November 2002) were compared with those obtained in the second period (January-March 2003), considering the sequence of the treatment, i.e. 'low-high' corresponding to low-EVOO in the first period and high-EVOO in the second period and 'high-low' corresponding to highEVOO in the first period and low-EVOO in the second period.

Indicated by $y_{i j k}$, the mean of the log-transformed values of the four responses observed on the $k$ th subject in the period $j=1,2$ of group $i=$ Low, High, we used the usual parameterisation, based on Jones \& Kenward (1989), $y_{i j k}=\mu+s_{i k}+$ $\pi_{j}+\tau_{i}+\lambda_{i j-1}+\epsilon_{i j k}$, where $\pi_{j}(j=1,2)$ are the period effects; $\tau_{i}(i=$ Low, High) are the direct treatment effects, $\lambda_{L, 1}$ and $\lambda_{H, 1}$ are the carry-over effect parameters; $s_{i k}$ are the random subject effects with mean 0 and variance $\sigma_{s}$ and $\epsilon_{i j k}$ are white-noise random error.

Exact non-parametric tests for two-period cross-over trials were applied (Jones \& Kenward, 1989). Two-sample exact Wilcoxon rank-sum tests were applied to assess, for each outcome, the hypothesis of equality of carry-over effect $H_{0}$ : $\lambda_{1}=\lambda_{2}$, treatment effect $H_{0}: \tau_{L}=\tau_{H} \mid \lambda_{1}=\lambda_{2}$ and period effect $H_{0}: \pi_{1}=\pi_{2} \mid \lambda_{1}=\lambda_{2}$ and to derive point estimates 
with $95 \% \mathrm{CI}$ for the exponential of the differences on treatment (the term $\exp \left(\tau_{H}=\tau_{L}\right)$ gives the geometric mean ratio by treatment group) and period (the term exp $\left(\pi_{1}-\pi_{2}\right)$ gives the geometric mean ratio by period). All analyses were carried out with STATA 7 (Stata Statistical Software release 7; StataCorp LP, College Station, TX, USA).

\section{Ethical considerations}

The study was approved by the Florence Health Authority's Ethics Committee. All study procedures conformed with the Declaration of Helsinki for medical research involving human subjects, as revised in 1983.

\section{Results}

The main baseline characteristics of study volunteers are shown in Table 2. The age range was 47-67 years; the average BMI was borderline normal (mean $25 \cdot 1$ (range 20.7-27.8) $\mathrm{kg} / \mathrm{m}^{2}$ ). The average daily energy intake was 9221 (SD 4224) $\mathrm{kJ}(2204$ (SD 1015) kcal), and was characterised by a $32.9 \%$ energy intake from fats, with olive oil as the most frequently consumed added fat $(32.8 \mathrm{~g} / \mathrm{d} v .0 .2 \mathrm{~g}$ seed oils, $0.6 \mathrm{~g}$ margarine and $0.6 \mathrm{~g}$ butter and $1.1 \mathrm{~g}$ other animal fats). Biochemical data measured at the baseline showed a mean cholesterol level of 5.88 (range $4.84-7.33$ ) mmol/l. No statistically significant differences were observed between sequence of treatment for any of the considered variables (data not shown).

Table 3 shows the average values of the outcomes of interest, at the baseline and during high-EVOO and low-EVOO treatment. The intake of total olive oil phenols, as estimated by the repeated $24 \mathrm{~h}$ recalls (four measurements per subject during high-EVOO and four during low-EVOO), was approximately four times higher during the treatment with highEVOO (mean 34.9 (SD 11.0) $\mathrm{mg} / \mathrm{d}$ ) as compared with the low-EVOO treatment (mean 9.7 (SD 3.4) $\mathrm{mg} / \mathrm{d}$ ), although the consumption of the study oil tended to be higher during the low-EVOO treatment (64.4 (SD 22.5) v. $53 \cdot 3$ (SD 16.1) g/d). Intake of free hydroxytyrosol was seven-fold during the high-EVOO. Baseline urinary excretion of hydroxytyrosol and of its metabolite HVAlc demonstrates that this Tuscan sample of women is habitually exposed to olive oil phenols: hydroxytyrosol excretion ranges from 116 to $3146 \mu \mathrm{g} / \mathrm{d}$, and HVAlc from 25 to $212 \mu \mathrm{g} / \mathrm{d}$. The increased intake of olive oil phenols affected the excretion of hydroxytyrosol and its metabolite HVAlc. Fig 2 shows the geometric means of cumulative urinary excretion of hydroxytyrosol and HVAlc, by treatment sequence and by period. Treatment and period effects were tested by exact non-parametric tests for twoperiod cross-over trials, on log-transformed data, and results are summarised in Table 4. The ratio of geometric means of the measurements showed a statistically significant increased

Table 2. Characteristics of the ten postmenopausal women at the baseline visit (Mean values and standard deviations)

\begin{tabular}{|c|c|c|c|c|}
\hline & Mean & SD & 10th Percentile & 90th Percentile \\
\hline Age (years) & $57 \cdot 1$ & $5 \cdot 9$ & $50 \cdot 4$ & $66 \cdot 0$ \\
\hline Weight (kg) & 60.9 & $9 \cdot 2$ & $49 \cdot 0$ & $71 \cdot 1$ \\
\hline Height (cm) & $155 \cdot 3$ & $8 \cdot 8$ & 1.42 & 1.66 \\
\hline BMI $\left(\mathrm{kg} / \mathrm{m}^{2}\right)$ & $25 \cdot 1$ & $2 \cdot 2$ & $21 \cdot 8$ & $27 \cdot 6$ \\
\hline Waist:hip ratio & 0.8 & $0 \cdot 1$ & 0.76 & 0.90 \\
\hline Systolic blood pressure (mm/Hg) & $122 \cdot 0$ & 14.9 & $107 \cdot 5$ & $145 \cdot 0$ \\
\hline Diastolic blood pressure $(\mathrm{mm} / \mathrm{Hg})$ & $72 \cdot 0$ & $6 \cdot 3$ & 62.5 & $80 \cdot 0$ \\
\hline Pulse rate (frequency/min) & $64 \cdot 6$ & 4.6 & 57.5 & $70 \cdot 0$ \\
\hline \multicolumn{5}{|l|}{ Average daily dietary intake* } \\
\hline \multicolumn{5}{|l|}{ Energy intake } \\
\hline $\mathrm{KJ}$ & 9221 & 4244 & 4487 & 15754 \\
\hline Kcal & 2204 & 1015 & 1073 & 3543 \\
\hline Protein (\% total energy) & $15 \cdot 6$ & $2 \cdot 3$ & 12.5 & 18.9 \\
\hline Carbohydrates (\% total energy) & $46 \cdot 4$ & $5 \cdot 4$ & $41 \cdot 0$ & $57 \cdot 0$ \\
\hline Fats (\% total energy) & 32.9 & 4.6 & $26 \cdot 3$ & $38 \cdot 2$ \\
\hline \multicolumn{5}{|l|}{ Vitamins } \\
\hline Vitamin C (mg) & $159 \cdot 7$ & $72 \cdot 4$ & 82.9 & $269 \cdot 1$ \\
\hline Vitamin E (mg) & $8 \cdot 0$ & 3.5 & 3.5 & $12 \cdot 2$ \\
\hline$\beta$-Carotene $(\mu \mathrm{g})$ & $4634 \cdot 8$ & $2701 \cdot 8$ & $1848 \cdot 5$ & $8853 \cdot 6$ \\
\hline Folates $(\mu \mathrm{g})$ & $307 \cdot 8$ & $129 \cdot 2$ & $168 \cdot 0$ & $485 \cdot 0$ \\
\hline Alcohol (g) & $17 \cdot 0$ & $11 \cdot 0$ & $2 \cdot 6$ & $27 \cdot 4$ \\
\hline \multicolumn{5}{|l|}{ Added fats $(\mathrm{g} / \mathrm{d})$} \\
\hline Olive oil & $32 \cdot 8$ & $19 \cdot 4$ & $11 \cdot 1$ & $61 \cdot 6$ \\
\hline Seed oils & 0.2 & 0.1 & 0.1 & 0.4 \\
\hline Margarine & 0.6 & $1 \cdot 1$ & 0.1 & $2 \cdot 1$ \\
\hline Butter & 0.6 & 0.8 & 0.1 & $2 \cdot 0$ \\
\hline Other animal fat & $1 \cdot 1$ & $1 \cdot 1$ & 0.0 & $2 \cdot 6$ \\
\hline \multicolumn{5}{|l|}{ Baseline blood levels } \\
\hline Total cholesterol (mmol/l) & $5 \cdot 88$ & 0.77 & 4.93 & $6 \cdot 95$ \\
\hline HDL-cholesterol (mmol/l) & 1.92 & 0.38 & 1.46 & $2 \cdot 49$ \\
\hline LDL-cholesterol (mmol/l) & 3.41 & 0.66 & 2.49 & $4 \cdot 13$ \\
\hline Triacylglycerol (mmol/l) & $1 \cdot 20$ & 0.61 & 0.73 & $2 \cdot 15$ \\
\hline Glucose (mmol/l) & 4.44 & 0.56 & $3 \cdot 33$ & $5 \cdot 00$ \\
\hline
\end{tabular}

* Data obtained from the food-frequency questionnaire administered at the baseline visit. For details of subjects and procedures, see p. 743 . 
Table 3. Summary of intakes, excretion, and biomarkers at baseline, and during high-phenol extra-virgin olive oil (high-EVOO) and low-phenol extra-virgin olive oil (low-EVOO) treatment

(Mean values and standard deviations)

\begin{tabular}{|c|c|c|c|c|c|c|}
\hline & \multicolumn{2}{|c|}{ Baseline $(n 10)$} & \multicolumn{2}{|c|}{ High -EVOO (n 40) } & \multicolumn{2}{|c|}{ Low-EVOO (n 40) } \\
\hline & Mean & SD & Mean & SD & Mean & SD \\
\hline \multicolumn{7}{|l|}{ Intake estimates from $24 \mathrm{~h}$ diet recalls } \\
\hline Olive oil $(g / d)^{*}$ & $24 \cdot 5$ & $8 \cdot 8$ & $53 \cdot 3$ & $16 \cdot 1$ & 64.4 & $22 \cdot 5$ \\
\hline Total olive oil phenols (mg/d) & $-\dagger$ & - & 34.9 & $11 \cdot 0$ & $9 \cdot 7$ & 3.4 \\
\hline Hydroxytyrosol (free form) (mg/d) & $-\dagger$ & - & 0.7 & 0.3 & $0 \cdot 1$ & $0 \cdot 1$ \\
\hline Total hydroxytyrosol (free and linked forms) (mg/d) & $-\dagger$ & - & $8 \cdot 4 \|$ & - & $1 \cdot 0 \|$ & - \\
\hline \multicolumn{7}{|l|}{$24 \mathrm{~h}$ urine excretion } \\
\hline Hydroxytyrosol ( $\mu \mathrm{g} / \mathrm{d})$ & $682 \cdot 0$ & $924 \cdot 6$ & $1347 \cdot 1 \ddagger$ & $1007 \cdot 2$ & $880 \cdot 1 \S$ & $1451 \cdot 7$ \\
\hline Homovanillyl alcohol ( $\mu \mathrm{g} / \mathrm{d})$ & $73 \cdot 8$ & $54 \cdot 6$ & $444 \cdot 1 \ddagger$ & $509 \cdot 0$ & $150 \cdot 7 \S$ & $128 \cdot 3$ \\
\hline \multicolumn{7}{|l|}{ Study biomarkers } \\
\hline Oxidised DNA bases (\% DNA in comet tail) & 11.9 & $7 \cdot 67$ & $5 \cdot 6 \ddagger$ & $5 \cdot 1$ & $6 \cdot 5$ & $5 \cdot 1$ \\
\hline Basal DNA breaks (\% DNA in comet tail) & $12 \cdot 9$ & $7 \cdot 0$ & $5 \cdot 1 \ddagger$ & 1.5 & $5 \cdot 0$ & $2 \cdot 3$ \\
\hline Plasma antioxidant capacity $(\mathrm{mmol} / \mathrm{l})$ & 0.9 & 0.3 & $0.9 \ddagger$ & 0.5 & 0.8 & 0.5 \\
\hline
\end{tabular}

excretion of hydroxytyrosol (treatment effect $2 \cdot 17 ; P=0 \cdot 01$ ), HVAlc (treatment effect 3.08; $P=0.019$ ), and total combined hydroxytyrosol and HVAlc excretion (treatment effect 1.94 ; $P=0.01$ ). Phenol excretion was not affected by period, and no carry-over was detectable for any of the outcomes (data not shown).

Fig 3 shows the geometric mean ratios of measured DNA oxidative damage by treatment sequence (high-EVOO $v$. low-EVOO) during the intervention period. Measurements were taken every 2 weeks. Although the effect was not constant over the treatment period, individual differences showed a reduction of damage mainly in the fourth and fifth measurement time (i.e. after 6 and 8 weeks of treatment).

Overall, the average of the four measurements during treatment with high-EVOO was always lower than the average during the low-EVOO treatment (Fig 4). The non-parametric tests (Table 4) showed a decreased DNA damage, with a $30 \%$ significant reduction of oxidised bases, expressed as the ratio of the geometric means of the repeated measures (treatment effect $0.70 ; 95 \%$ CI $0.56,0.86 ; P=0.019$ ); a nonsignificant period effect (lower damage in the winter period) was also shown. Restricting the analyses on measurements taken after 6 and 8 weeks, an even stronger result could be observed (treatment effect $0.53 ; 95 \%$ CI $0.33,0.76$; data not shown). DNA breaks were not affected by treatment $(P=0.352)$, but were strongly influenced by study period, with lower breaks in January-March (period effect 0.62; $P=0 \cdot 01$ ). Treatment did not affect plasma antioxidant capacity, but this measure was also affected by period (period effect $0.64 ; P=0 \cdot 01$ ).

The response of lymphocytes to in vitro induced oxidative stress was evaluated at the first and fifth measurement time in both study periods (i.e. at baseline and after 8 weeks of treatment). No difference in the amount of DNA breakage induced by $\mathrm{H}_{2} \mathrm{O}_{2}$ was found between high-EVOO and lowEVOO treatment (data not shown).
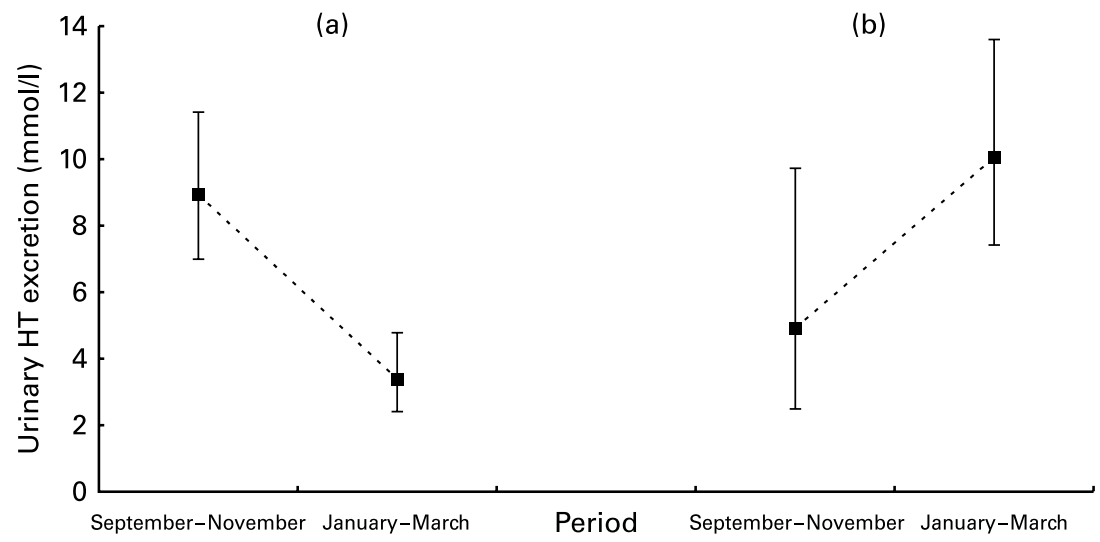

Fig. 2. Total combined urinary excretion of hydroxytyrosol and homovanillyl alcohol (mmol/l) in ten volunteer subjects by period and treatment sequence. (a) Highphenol extra-virgin olive oil (high-EVOO) in the first period and low-phenol EVOO (low-EVOO) in the second period; (b) low-EVOO in the first period and highEVOO in the second period). Values are geometric means, with $95 \% \mathrm{Cl}$ represented by vertical bars. For details of subjects and procedures, see p. 743. 
Table 4. Summary of treatment and period effects during high-phenol olive oil (high-EVOO) and low-phenol olive oil (low-EVOO) intervention

(Geometric mean ratios and $95 \%$ confidence intervals)

\begin{tabular}{|c|c|c|c|c|}
\hline \multicolumn{5}{|l|}{ Intake estimates from $24 \mathrm{~h}$ diet recalls } \\
\hline Total olive oil phenols intake (mg/24 h) & $3.56^{*}$ & $3.01,4 \cdot 20$ & 0.99 & $0.83,1.14$ \\
\hline Hydroxytyrosol excretion ( $\mu \mathrm{g} / 24 \mathrm{~h})$ & $2 \cdot 17^{\star}$ & $1.33,5.54$ & 0.86 & $0.61,1 \cdot 71$ \\
\hline Homovanillyl alcohol excretion ( $\mu \mathrm{g} / 24 \mathrm{~h})$ & $3.08^{*}$ & $1 \cdot 49,5 \cdot 10$ & 1.63 & $0.74,2 \cdot 74$ \\
\hline Hydroxytyrosol and homovanillyl alcohol excretion (mmol/l) & $1.94^{*}$ & $1.39,4.06$ & 0.84 & $0.50,1.62$ \\
\hline Basal DNA breaks (\% DNA in comet tail) & 0.96 & $0.84,1.08$ & $0.62^{*}$ & $0.53,0.70$ \\
\hline Plasma total antioxidant capacity (mmol/l) & 1.09 & $0.94,1.24$ & $0.64^{*}$ & $0.55,0.72$ \\
\hline
\end{tabular}

${ }^{*} P<0.05$; exact non-parametric tests; Jones \& Kenward (1989)

For details of subjects and procedures, see p. 743.

\section{Discussion}

Olive oil is the characterising ingredient of diets in the Mediterranean basin and the hypothesis that high intakes of olive oil could reduce cancer incidence is appealing (Willett 1997; Simopoulos, 2004; Visioli et al. 2004). Despite the limited number of subjects, the present cross-over trial was able to show a reduction in DNA oxidative damage in postmenopausal women consuming an EVOO with a high concentration of total phenols, and of the potent antioxidant hydroxytyrosol. In the high-EVOO the total content of hydroxytyrosol, both free and linked, was about ten-fold higher than in the low-EVOO.

The detection of phenols in EVOO is quite recent (Montedoro et al. 1992a,b) and various researchers have focused their attention on their effects (Visioli et al. 1999; Pirisi et al. 2000; Romani et al. 2001; Conte et al. 2002; Pinelli et al. 2003; Mulinacci et al. 2005b). Phenols comprise a large family of molecules and the most abundant in EVOO are tyrosol, hydroxytyrosol, and other complex secoiridoids, sharing the hydroxytyrosol or tyrosol nucleus. They are the major determinants of sensorial characteristics of EVOO and their concentration in the oil is related to several factors: cultivar and environmental characteristics, ripeness of the fruit, and time and type of milling process. Hydroxytyrosol has powerful antioxidant potentials (Papadopoulos \& Bosku, 1991), protects
LDL from oxidative damage (Visioli et al. 1995; Caruso et al. 1999; Ramirez-Tortosa et al. 1999; Fito et al. 2000) and decreases $\mathrm{F}_{2}$-isoprostanes excretion (Visioli et al. 2000a). However, the effect on lipid oxidation was evidenced by some (Gimeno et al. 2002; Marrugat et al. 2004; Weinbrenner et al. 2004) but not all intervention trials (Vissers et al. 2001; Moschandreas et al. 2002).

The focus of our intervention was the effect of hydroxytyrosol on DNA oxidation, since a reduction of DNA oxidative damage is a mechanism underlying possible cancer prevention by olive oil. Mammalian cells are continuously attacked by oxygen radicals and such damage, if not appropriately counteracted, contributes to generation of DNA damage and somatic cell mutation that could direct the cell to a cancerous transformation (Halliwell, 2000; Marnett, 2000; Neumann et al. 2003; Saran et al. 2004). Deiana et al. (1999) showed an inhibition of the peroxynitrate-dependent DNA base modification in vitro. An in vitro study (Quiles et al. 2002) showed a lower DNA damage exerted by hydroxytyrosol on human prostate cells. A recent trial with three olive oils with different concentration of total phenols showed an effect on the oxidant-antioxidant status of human cells. In particular, 8-oxo$2^{\prime}$-deoxyguanosine in mitochondrial DNA was reduced by the intake of olive oil phenols in men consuming a verylow-antioxidant diet (Weinbrenner et al. 2004). Additionally,

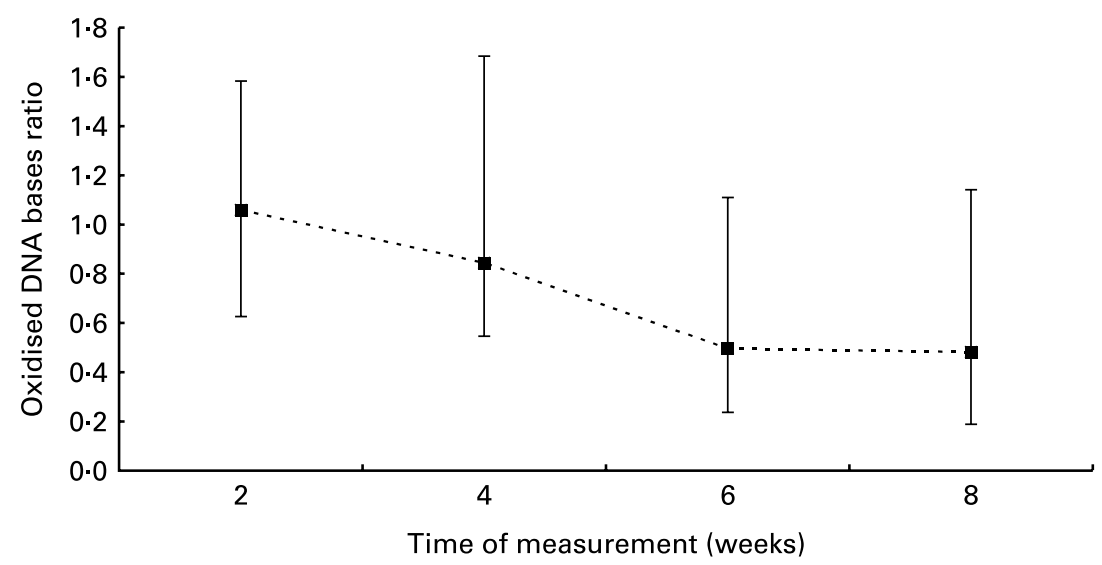

Fig. 3. Oxidised DNA bases in ten volunteer subjects, as measured by the comet assay: between high-phenol extra-virgin olive oil $v$. low-phenol extra-virgin olive oil treatment period, measured every 2 weeks. Values are geometric mean ratios, with $95 \% \mathrm{Cl}$ represented by vertical bars. For details of subjects and procedures, see p. 743. 


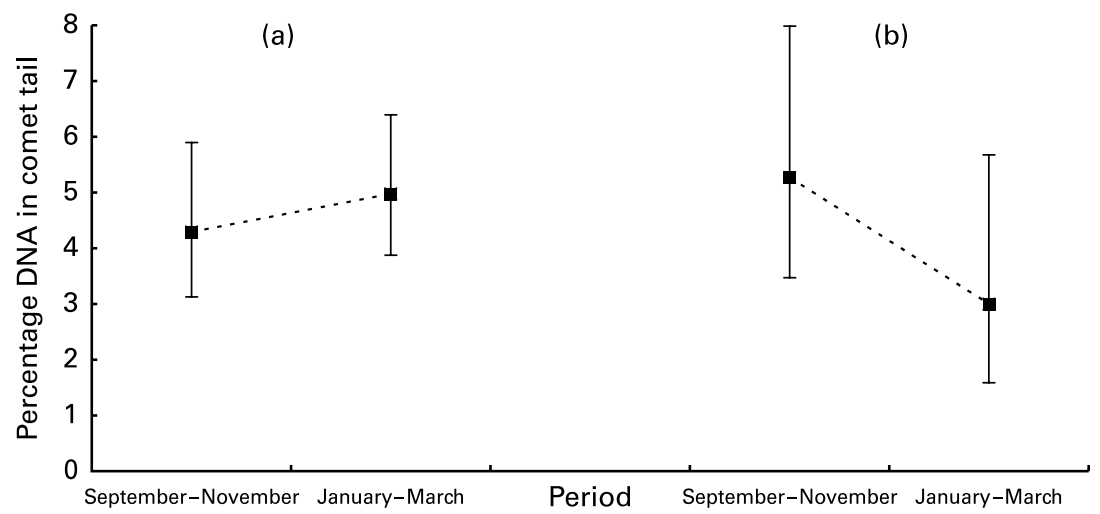

Fig. 4. Oxidised DNA bases (\% DNA in comet tail) by period and treatment sequence. (a) High-phenol extra-virgin olive oil (high-EVOO) in the first period and low-phenol EVOO (low-EVOO) in the second period; (b) low-EVOO in the first period and high-EVOO in the second period. Values are geometric means, with $95 \% \mathrm{Cl}$ represented by vertical bars. For details of subjects and procedures, see p. 743.

in a sample of 100 volunteers randomly selected from a large prospective study conducted in Europe - the EPIC Study (Palli et al. 2000) - a negative association was observed between amounts of olive oil consumption and DNA adduct formation.

As a measure of DNA damage we used single-cell microgel electrophoresis, or comet assay; this is a very sensitive method initially developed as a modification of the alkaline elution technique for the study of single- and double-strand DNA breaks (Singh et al. 1988). It involves embedding individual cells in agarose on a microscope slide and measuring the degree of migration of nuclear DNA upon electrophoresis in an alkaline buffer. The extent of migration is proportional to the number of breaks in the DNA molecule. A modification of the method has been described, that allows the detection of specific lesions on DNA, such as oxidation of either purines or pyrimidines, by the addition of endonucleases cleaving DNA at damaged sites (Collins et al. 1993). Thus, it is possible with the comet assay to study both DNA breaks and specific oxidative damage at the single-cell level. This procedure has been used to study basal oxidative damage in animal models (Giovannelli et al. 2000) and in different tissues and cells, including human lymphocytes (Pool-Zobel et al. 1997; Collins et al. 1998). In the present study, DNA bases were shown to be protected by olive oil phenols, although the result was not evident for DNA strand breaks.

The present study evidenced also a statistically significant period effect, when observing DNA breaks. These were higher at the first baseline, i.e. in the period immediately following the summer months, an association that is probably the result of exposure to UV radiation, as was also recently shown in other studies from our group (Giovannelli et al. 2002, 2005).

Compliance is a critical aspect of intervention trials. Subjects recruited for the present study were women in their fifties and sixties, a population group that, in Italy, tends to consume their meals at home and to be personally responsible for food preparation. In fact, the study results show a very strong compliance to the randomly assigned treatment; olive oil consumption doubled with regard to baseline estimates, resulting in a remarkable increase of urinary excretion of hydroxytyrosol and its metabolite, even in subjects assigned to the low-EVOO group. Although baseline excretion clearly demonstrates a chronic exposure to EVOO, their quality, in terms of phenol concentration, is currently unknown. The availability of a marker of olive oil phenol intake is particularly important in current research. Large epidemiological studies, such as the EPIC study, currently conducted in ten European countries, offer the possibility of measuring markers of dietary intakes of food, nutrients and even contaminants. Biological samples for almost half a million subjects across Europe were collected at the baseline. Such samples could even be used to characterise dietary patterns in different Mediterranean and European populations, not only in terms of fruit and vegetables, using circulating carotenoids as markers of intake (Al-Delaimy et al. 2005), but also in terms of types and quality of ingested olive oils.

Epidemiological studies based in the Mediterranean have shown a protection from cancer at higher levels of intake of olive oil (Martin-Moreno et al. 1994; La Vecchia et al. 1995; Trichopoulou et al. 1995; Braga et al. 1998; Franceschi et al. 1999). Unfortunately, due to the limited consumption of this type of fat in non-Mediterranean countries, such results have not been replicated and confirmed, to date, in other parts of Europe or of the Western world. Moreover, questionnaires so far adopted in such epidemiological studies have not allowed the exploration of the different roles of different olive oils types (i.e. olive oil $v$. EVOO). Most studies were designed when little was known about phenols in olive oils available on the market and not much detail was included in questionnaires. This could probably explain why Greek researchers (Trichopoulou et al. 2003) did not find a significantly protective effect of olive oil (subjects could be consuming a larger proportion of olive oil than EVOO), despite the general strong protection of the Mediterranean diet index evidenced by their analyses based on the Greek component of the EPIC study. Recently, re-interviewing approximately 2000 women from the Florence EPIC study, we observed that EVOO are used by most Florentine women for cooking and seasoning (G Masala and D Palli, unpublished results). This epidemiological finding is confirmed by the present intervention trial, showing a sustained excretion of hydroxytyrosol and of its metabolite HVAlc in baseline $24 \mathrm{~h}$ urine samples.

Two batches of EVOO, instead of simple olive oils with fixed amounts of phenols added, or, more extremely, ad hoc prepared supplements with known concentration of the phenols of interest, were used as treatment in the present study. 
These alternative possibilities had been considered and discarded. First of all, we wanted as much as possible to approximate a 'real-life' situation. The Tuscan population is normally 'exposed' to olive oil and it is used to the consumption of high-quality EVOO. If we had supplemented a simple, nonEVOO with known quantities of antioxidants, subjects would have been forced to consume this low-quality olive oil for two periods of 8 weeks (about 2 months) each and we thought this approach was not ethical. We also decided against the use of capsules with hydroxytyrosol and other phenols, being interested in the effect of a complex mixture of phenols from real food. Moreover, a higher bioavailability of hydroxytyrosol as a natural component of EVOO was demonstrated by previous work; a higher recovery of hydroxytyrosol was observed when free hydroxytyrosol was administered as EVOO, as compared with the recovery measured when the vehicle of administration of free hydroxytyrosol was a refined olive oil or a yoghurt (Visioli et al. 2003).

Our finding that EVOO phenols protect from oxidative damage in healthy postmenopausal women needs to be reproduced in larger intervention studies on subjects of both sexes, in different age groups, and possibly also in populations not chronically exposed to EVOO, but offers, in vivo, new and strong evidence of the protection exerted by high-phenol olive oils in human subjects.

\section{Acknowledgements}

We are thankful to the volunteer women who enthusiastically participated in this trial, and to their families who supported them during the demanding study period. We would like to specially thank Professor Giovanni Galli, University of Milan (deceased), who inspired research in this field during the last decade. We are indebted to Donatella Landini (nurse) for blood drawing and other clinical assessments; to Chiara Zappitello and Vanessa Visentin for skilled and patient editorial and secretarial assistance; to Andrea Ichino (European University Institute, Florence) for deep and fruitful discussions and to Walter Willett (Harvard School of Public Health, Boston, MA, USA), for his supportive encouragement and for useful suggestions. Finally, we are thankful to Dr Alissa Mattei (Carapelli SpA, Tavarnelle Val di Pesa, Florence, Italy) for sharing with us her expertise and profound knowledge of olive oils, advising on the study structure and providing the oils used in the trial. Study oils were selected, bottled and provided free of charge by Carapelli Firenze S.p.A, Tavarnelle Val di Pesa, Florence, Italy. The Italian League against Cancer (Florence section) contributed to the project. The study was supported by a grant from the Associazione Italiana per la Ricerca sul Cancro (AIRC), Milan, Italy. V. P. was an AIRC fellow.

\section{References}

Al-Delaimy WK, Slimani N, Ferrari P, et al. (2005) Plasma carotenoids as biomarkers of intake of fruits and vegetables: ecologicallevel correlations in the European Prospective Investigation into Cancer and Nutrition (EPIC). Eur J Clin Nutr 59, 1397-1408.

Braga C, La Vecchia C, Franceschi S, Negri E, Parpinel M, Decarli A, Giacosa A \& Trichopoulos D (1998) Olive oil, other seasoning fats, and the risk of colorectal carcinoma. Cancer 82, 448-453.
Caruso D, Berra B, Giavarini F, Cortesi N, Fedeli E \& Galli G (1999) Effect of virgin olive oil phenolic compounds on in vitro oxidation of human low density lipoproteins. Nutr Met Cardiovasc Dis 9, $102-107$.

Caruso D, Visioli F, Patelli R, Galli C \& Galli G (2001) Urinary excretion of olive oil phenols and their metabolites in humans. Metabolism 50, 1426-1428.

Collins A, Duthie SJ \& Dobson VL (1993) Direct enzymic determination of oxidative damage in human lymphocyte DNA. Carcinogenesis 14, 1733-1735.

Collins AR, Olmedilla B, Southon S, Granado F \& Duthie S (1998) Serum carotenoids and oxidative DNA damage in human lymphocytes. Carcinogenesis 19, 2159-2162.

Conte LS, Pizzale L, Bortolomeazzi R \& Vichi S (2002) Valutazione dell'attività antiossidante di oli extra vergini di oliva (Appraisal of the antioxidant activity in extra virgin olive oil). Prog Nutr 4, 17-23.

Deiana M, Aroma OI, Bianchi ML, Spencer JP, Kaur H, Halliwell B, Aeschbach R, Banni S, Dessi MA \& Corongiu FP (1999) Inhibition of peroxynitrite dependent DNA base modification and tyrosine nitration by the extra virgin olive oil-derived antioxidant hydroxytyrosol. Free Radical Bio Med 26, 762-769.

Dieffenbacher A \& Pocklington WD (1992) Determination of tocopherols and tocotrienols in vegetable olis and fats by high performance liquid chromatography. In Standard Methods for the Analysis of Oils, Fats and Derivatives, [A Dieffenbacher and WD Pocklington, editors]. London: Blackwell Scientific Publications.

European Commission (2003) Commission Regulation (EC) No. 1989/ 2003 of 6 November 2003 amending Regulation (EEC) no. 2568/91 on the characteristics of olive oil and olive-pomace oil and on the relevant methods of analysis. In Official Journal of the European Union, pp. vol. 46, L295, 57-77. Brussels: European Commission.

Fito M, Covas MI, Lamuela-Raventos RM, Vila J, Torrentes L, de la Torre C \& Marrugat J (2000) Protective effect of olive oil and its phenolic compounds against low density lipoprotein oxidation. Lipids 35, 633-638.

Franceschi S, Favero A, Conti E, Talamini R, Volpe R, Negri E, Barzan L \& La Vecchia C (1999) Food groups, oil and butter, and cancer of the oral cavity and pharynx. Br J Cancer 80, 614-620.

Gimeno E, Fito M, Lamuela-Raventos RM, Castellote AI, Covas M, Farre M, de La Torre-Boronat MC \& Lopez-Sabater MC (2002) Effect of ingestion of virgin olive oil on human low-density lipoprotein composition. Eur J Clin Nutr 56, 114-120.

Giovanelli L, Pitozzi V, Moretti S, Boddi V \& Dolara P (2005) Seasonal variations of DNA damage in human lymphocytes: Correlation with different environmental variables. Mutat Res 8 August (Epublication ahead of print version).

Giovannelli L, Pitozzi V, Riolo S \& Dolara P (2003) Measurement of DNA breaks and oxidative damage in polymorphonuclear and mononuclear white blood cells: a novel approach using the comet assay. Mutat Res 538, 71-80.

Giovannelli L, Saieva C, Masala G, Testa G, Salvini S, Pitozzi V, Riboli E, Dolara P \& Palli D (2002) Nutritional and lifestyle determinants of DNA oxidative damage: a study in a Mediterranean population. Carcinogenesis 23, 1483-1489.

Giovannelli L, Testa G, De Filippo C, Cheynier V, Clifford MN \& Dolara P (2000) Effect of complex polyphenols and tannins from red wine on DNA oxidative damage of rat colon mucosa in vivo. Eur J Nutr 39, 207-212.

Halliwell B (2000) Why and how should we measure oxidative DNA damage in nutritional studies? How far have we come?" Am J Clin Nutr 72, 1082-1087.

IUPAC (1987) IUPAC Standard Method 2.301. Preparation of fatty acid methyl ester. In Standard Methods for the Analysis of Oils, Fats and Derivatives, 7th ed. [C Paquot and A Hautfenne, editors]. Oxford: Blackwell Scientific Publications.

Jones B \& Kenward MG (1989) Design and Analysis of Cross-over Trials. London: Chapman, Hall. 
La Vecchia C, Negri E, Franceschi S, Decarli A, Giacosa A \& Lipworth L (1995) Olive oil, other dietary fats, and risk of breast cancer (Italy). Cancer Causes Control 6, 545-550.

Marnett LJ (2000) Oxyradicals and DNA damage. Carcinogenesis 21, $361-370$.

Marrugat J, Covas MI, Fito M, Schroder H, Miro-Casas E, Gimeno E, Lopez-Sabater MC, de la Torre R \& Farre MSOLOS Investigators (2004) Effects of differing phenolic content in dietary olive oils on lipids and LDL oxidation - a randomized controlled trial. Eur $J$ Nutr 43, 140-147.

Martin-Moreno JM, Willett WC, Gorgojo L, Banegas JR, RodriguezArtalejo F, Fernandez-Rodriguez JC, Maisonneuve P \& Boyle P (1994) Dietary fat, olive oil intake and breast cancer risk. Int $J$ Cancer 58, 774-780.

Miller NJ, Rice-Evans C, Davies MJ, Gopinathan V \& Milner A (1993) A novel method for measuring antioxidant capacity and its application to monitoring the antioxidant status in premature neonates. Clin Sci 84, 407-412.

Montedoro G, Servili M, Baldioli M \& Miniati E (1992a) Simple and hydrolyzable compounds in virgin olive oil. 1. Their extraction, separation, and quantitative and semiquantitative evaluation by HPLC. J Agric Food Chem 40, 1571-1576.

Montedoro G, Servili M, Baldioli M \& Miniati E (1992b) Simple and hydrolyzable compounds in virgin olive oil. 2. Initial characterization of the hydrolyzable fraction. J Agric Food Chem 40, $1577-1580$.

Moschandreas J, Vissers MN, Wiseman S, van Putte KP \& Kafatos A (2002) Extra virgin olive oil phenols and markers of oxidation in Greek smokers: a randomized cross-over study. Eur J Clin Nutr 56, 1024-1029.

Mulinacci N, Giaccherini C, Ieri F, Romani A \& Vincieri FF (2006a) Evaluation of lignans and free and linked hydroxy-tyrosol and tyrosol in extra virgin olive oil after hydrolysis processes. $J$ Science Food Agric (In the Press).

Mulinacci N, Giaccherini C, Innocenti M, Romani A, Vincieri FF, Marotta F \& Mattei A (2006b) Analysis of extra virgin olive oils from stoned olives. J Science Food Agric (In the Press).

Neumann CA, Krause DS, Carman CV, Das S, Dubey DP, Abraham JL, Bronson RT, Fujiwara Y, Orkin SH \& van Etten RA (2003) Essential role for the peroxiredoxin Prdx1 in erythrocyte antioxidant defence and tumour suppression. Nature 424, 561-565.

Owen RW, Haubner R, Wurtele G, Hull E, Spiegelhalder B \& Bartsch H (2004) Olives and olive oil in cancer prevention. Eur $J$ Cancer Prev 13, 319-326.

Pala V, Sieri S, Palli D, et al. (2003) Diet in the Italian EPIC cohorts: presentation of data and methodological issues. Tumori 89, 594-607.

Palli D, Vineis P, Russo A, et al. (2000) Diet, metabolic polymorphisms and DNA adducts: the EPIC-Italy cross-sectional study. Int $J$ Cancer 87, 444-451.

Papadopoulos G \& Boskou D (1991) Antioxidant effect of natural phenols on olive oil. J Am Oil Chem Soc 68, 669-671.

Pinelli P, Galardi C, Mulinacci N, Vincieri FF, Cimato A \& Romani A (2003) Minor polar compounds and fatty acid analyses in mono cultivar virgin olive oils from Tuscany. Food Chem 80, 331-336.

Pirisi FM, Cabras P, Falqui Cao C, Migliorini M \& Muggelli M (2000) Phenolic compounds in virgin olive oil. 2. Reappraisal of the extraction, HPLC separation, and quantification procedures. J Agric Food Chem 48, 1191-1196.

Pisani P, Faggiano F, Krogh V, Palli D, Vineis P \& Berrino F (1997) Relative validity and reproducibility of a food frequency dietary questionnaire for use in the Italian EPIC centres. Int J Epidemiol 26, S152-S160.

Pool-Zobel BL, Bub A, Müller H, Wollowski I \& Rechkemmer G (1997) Consumption of vegetables reduces genetic damage in humans: first results of a human intervention trial with carotenoirich foods. Carcinogenesis 18, 1847-1850.

Quiles JL, Farquharson AJ, Simpson DK, Grant I \& Wahle KW (2002) Olive oil phenolics: effects on DNA oxidation and redox enzyme mRNA in prostate cells. Br J Nutr 88, 225-234, discussion 223-224.

Ramirez-Tortosa MC, Urbano G, Lopez-Jurado M, Nestares T, Gomez MC, Mir A, Ros E, Mataix J \& Gil A (1999) Extravirgin olive oil increases the resistance of LDL to oxidation more than refined olive oil in free-living men with peripheral vascular disease. J Nutr 129, 2177-2183.

Romani A, Pinelli P, Mulinacci N, Galardi C, Vincieri FF, Liberatore L \& Cichelli A (2001) HPLC and HRGC analyses of polyphenols and secoiridoids in olive oil. Chromatographia 53, 279-284.

Salvini S, Parpinel M, Gnagnarella P, Maisonneuve P \& Turrini A (1998) Banca Dati di Composizione degli Alimenti per Studi Epidemiologici in Italia. Milan: Istituto Europeo di Oncologia.

Saran A, Spinola M, Pazzaglia S, et al. (2004) Loss of tyrosinase activity confers increased skin tumor susceptibility in mice. Oncogene 23, 4130-4135.

Simopoulos AP (2004) The traditional diet of Greece and cancer. Eur $J$ Cancer Prev 13, 219-230.

Singh NP, McCoy MT, Tice RR \& Schneider EL (1988) A simple technique for the quantitation of low level DNA damage in individual cells. Exp Cell Res 175, 184-191.

Trichopoulou A, Costacou T, Bamia C \& Trichopoulos D (2003) Adherence to a Mediterranean diet and survival in a Greek population. $N$ Engl J Med 348, 2599-2608.

Trichopoulou A, Katsouyanni K, Stuver S, Tzala L, Gnardellis C, Rimm E \& Trichopoulos D (1995) Consumption of olive oil and specific food groups in relation to breast cancer risk in Greece. J Natl Cancer Inst 87, 110-116.

Visioli F, Bellomo G, Montedoro G \& Galli C (1995) Low density lipoprotein oxidation is inhibited in vitro by olive oil constituents. Atherosclerosis 117, 25-32.

Visioli F, Caruso D, Galli C, Viappiani S, Galli G \& Sala A (2000a) Olive oils rich in natural catecholic phenols decrease isoprostane excretion in humans. Biochem Biophys Res Commun 278, 797-799.

Visioli F, Caruso D, Plasmati E, Patelli R, Mulinacci N, Romani A, Galli G \& Galli C (2001) Hydroxytyrosol, as a component of olive mill waste water, is dose-dependently absorbed and increases the antioxidant capacity of rat plasma. Free Radic Res 34, 301-305.

Visioli F, Galli C, Bornet F, Mattei A, Patelli R, Galli G \& Caruso D $(2000 b)$ Olive oil phenolics are dose-dependently absorbed in humans. FEBS Lett 468, 159-160.

Visioli F, Galli C, Grande S, Colonnelli K, Patelli C, Galli G \& Caruso D (2003) Hydroxytyrosol excretion differs between rats and humans and depends on the vehicle of administration. $J$ Nutr 133, 2612-2615.

Visioli F, Grande S, Bogani P \& Galli C (2004) The role of antioxidants in the Mediterranean diets: focus on cancer. Eur J Cancer Prev 13, 337-343.

Visioli F, Romani A, Mulinacci N, Zarini S, Conte D, Vincieri FF \& Galli C (1999) Antioxidant and other biological activities of olive oil mill waste waters. J Agric Food Chem 47, 3397-3401.

Vissers MN, Zock PL, Wiseman SA, Meyboom S \& Katan MB (2001) Effect of phenol-rich extra virgin olive oil on markers of oxidation in healthy volunteers. Eur J Clin Nutr 55, 334-341.

Weinbrenner T, Fito M, de la Torre R, et al. (2004) Olive oils high in phenolic compounds modulate oxidative/antioxidative status in men. J Nutr 134, 2314-2321.

Willett W (1997) Specific fatty acids and risks of breast and prostate cancer. Am J Clin Nutr 66, $1557 \mathrm{~S}-1563 \mathrm{~S}$. 